\title{
Detecção de anticorpos anti-Rickettsia rickettsii em cães residentes em área negligenciada no município de São Paulo, SP, Brasil
}

\author{
[Detection of anti-Rickettsia rickettsii antibodies in dogs living in a neglected area
} in São Paulo, SP, Brazil]

\author{
Z.Ê.S. Souza ${ }^{1}$, B.V. Moraes ${ }^{1,3}$, F.S. Krawczak ${ }^{2}$, L. Zulzke ${ }^{1}$, T.V. Carvalho' ${ }^{1}$, A.O. Sousa ${ }^{3}$, \\ R.G. Agopian ${ }^{1}$, A. Marcili ${ }^{1,3}$, M.B. Labruna ${ }^{3}$, J. Moraes-Filho ${ }^{1,3^{*}}$ \\ ${ }^{1}$ Medicina veterinária - Universidade Santo Amaro - São Paulo, SP \\ ${ }^{2}$ Escola de Veterinária e Zootecnia - Universidade Federal de Goiás - Goiânia, GO \\ ${ }^{3}$ Faculdade de Medicina Veterinária e Zootecnia - Universidade de São Paulo - São Paulo, SP
}

\begin{abstract}
RESUMO
A febre maculosa brasileira (FMB), descrita inicialmente nos Estados Unidos como febre maculosa das Montanhas Rochosas, é uma antropozoonose relatada apenas no continente americano e causada pela bactéria Rickettsia rickettsii. No Brasil a transmissão ocorre sobretudo pela picada de carrapatos do gênero Amblyomma spp. A doença foi inicialmente descrita como de transmissão em áreas rurais e silvestres, no entanto áreas periurbanas e urbanas vêm apresentando casos, principalmente relacionados com a presença de humanos residindo em pequenos fragmentos de mata ciliar. O presente estudo teve por objetivo elucidar a dispersão da FMB nas proximidades dos reservatórios Guarapiranga e Billings, na cidade de São Paulo, SP. Para tanto, a presença de anticorpos anti-R. rickettsii, Rickettsia parkeri e Rickettsia bellii foi avaliada em cães atendidos nas campanhas de esterilização cirúrgica e residentes ao redor dos reservatórios. Foram coletadas amostras de 393 cães, e as amostras de soro foram analisadas pela reação de imunofluorescência indireta (RIFI), com ponto de corte de 1:64. Os títulos para $R$. rickettsii variaram de 256 a 4096, com positividade de 3,3\% (13/393); para $R$. bellii, de 128 a 1024 e 4,1\% (16/393) de positivos, e um único animal $(0,25 \%)$ foi soropositivo para $R$. parkeri, com título de 128 . Os achados permitem concluir que a região de estudo apresenta condições de se tornar uma possível área com casos de FMB, pois comporta fragmentação de Mata Atlântica, condições essas ideais para a manutenção do vetor do gênero Amblyomma já descrito na região, bem como para a presença da Rickettsia rickettsii circulante entre os cães, confirmada pela existência de anticorpos. Condutas referentes à conscientização da população por meio de trabalhos educacionais devem ser implantadas para a prevenção da doença na população da área.
\end{abstract}

Palavras-chave: febre maculosa brasileira, imunofluorescência indireta, carrapatos, Amblyomma aureolatum

\begin{abstract}
Brazilian Spotted Fever (BSF), initially described in the United States as Rocky Mountain Spotted Fever, is an anthropozoonosis reported only in the Americas and caused by the bacterium Rickettsia rickettsii. In Brazil, transmission occurs mainly through tick bites of the genus Amblyomma spp. The disease was initially described as transmission of rural and wild areas; however, peri-urban and urban areas have been presenting cases, mainly related to the presence of humans residing in small fragments of riparian forest. The present study aimed to elucidate the dispersal of BSF near the Guarapiranga and Billings Reservoirs, in the city of São Paulo, SP. The presence of anti-R. rickettsii, Rickettsia parkeri and Rickettsia bellii antibodies were evaluated in dogs treated in surgical sterilization campaigns and residents around the Reservoirs. Samples were collected from 393 dogs and serum samples were analyzed by indirect immunofluorescence reaction (RIFI) with a cutoff of 1:64. The titles for R. rickettsii varied from 256 to 4096 with a positivity of 3.3\% (13/393); for R. bellii from 128 to 1024 and 4.1\% (16/393) of positive and a
\end{abstract}

Recebido em 23 de setembro de 2019

Aceito em 4 de junho de 2020

*Autor para correspondência (corresponding author)

E-mail: jonasmfilho@ hotmail.com 
single animal (0.25\%) was seropositive for $R$. parkeri with a titre of 128 . The findings allow us to conclude that the study region has conditions to become a possible area with BSF cases, as it involves Atlantic Forest, ideal conditions for the maintenance of the vector of the genus Amblyomma already described in the region and the presence of circulating Rickettsia rickettsii among dogs, confirmed by the presence of antibodies. Conducts regarding the awareness of the population through educational work should be implemented to prevent the disease in the population of the area.

Keywords: Brazilian spotted fever, indirect immunofluorescence, ticks, Amblyomma aureolatum

\section{INTRODUÇÃO}

A febre maculosa brasileira (FMB), também conhecida como febre maculosa das Montanhas Rochosas, nos Estados Unidos, é uma antropozoonose relatada apenas nas Américas, tendo a bactéria Rickettsia rickettsii como o agente etiológico. A bactéria é transmitida por vetores e, no Brasil, ocorre principalmente pela picada de carrapatos do gênero Amblyomma spp. (Guedes et al., 2005; Pinter, Labruna, 2006; Chen, Sexton, 2008; Labruna, 2009; Labruna et al., 2011; Pinter et al., 2011; Parola et al., 2013). O gênero Rickettsia foi classificado em quatro grupos: grupo da febre maculosa (GFM), grupo do tifo (TG), grupo de transição (TRG) e grupo ancestral (AG) (Parola et al., 2013). No Brasil, foram descritas, até o momento, sete espécies de Rickettsia, sendo quatro pertencentes ao grupo GFM: $R$. rickettsii, $R$. parkeri, $R$. rhipicephallii e $R$. amblyommatis (Labruna, 2009).

Amblyomma sculptum (previamente identificado como Amblyomma cajennense) é o principal vetor da FMB, e as capivaras (Hydrochoerus hydrochaeris) atuam como hospedeiro amplificador de Rickettsia rickettsii (Souza et al., 2009; Ramirez-Hernandez et al., 2020). A FMB foi descrita como uma doença de transmissão em áreas rurais e silvestres, no entanto áreas periurbanas e urbanas vêm apresentando casos, principalmente relacionados com o aumento da densidade de humanos residindo em pequenos fragmentos de florestas (Ogrzewalska et al., 2012; Souza et al., 2015; Scinachi et al., 2017).

No estado de São Paulo, ocorre a maior concentração de número de casos de FMB no país. $\mathrm{O}$ carrapato A. sculptum é o principal vetor da doença em áreas rurais, e Amblyomma aureolatum é o vetor nas áreas urbanas (Lemos et al., 1996; Horta et al., 2007; Brasil, 2019). Amblyomma aureolatum tem como hospedeiros naturais os passeriformes e os roedores, durante as fases imaturas do carrapato e, quando adultos, parasitam carnívoros silvestres e o cão doméstico (Fonseca, 1935; Arzua et al., 2003; Ogrzewalska et al., 2012). Os cães que têm acesso a fragmentos de Mata Atlântica promovem a veiculação do carrapato infectado da mata às residências, infectando, assim, os humanos. Na Região Metropolitana de São Paulo, ainda não foram elucidados quais são os hospedeiros amplificadores silvestres e se esses realmente ocorrem (Pinter et al., 2004; Moraes-Filho et al., 2009; Ogrzewalska et al., 2012; Scinachi et al., 2017).

O presente estudo objetivou avaliar a circulação de bactérias do grupo da febre maculosa $(R$. rickettsii, Rickettsia parkeri) e Rickettsia bellii, em cães residentes no município de São Paulo, onde já ocorreram óbitos em humanos por FMB e onde o vetor $A$. aureolatum é comumente encontrado (Pinter et al., 2016; São Paulo, 2019).

\section{MATERIAL E MÉTODOS}

Os reservatórios Guarapiranga e Billings são responsáveis pelo abastecimento de grande parte da água da Grande São Paulo e possuem, respectivamente, 37.827ha e 47.547ha. Estima-se que nessa região residam 600 mil habitantes. Por ser uma área de mananciais, uma grande parte dela é protegida por lei de conservação da fauna e flora nativas. $\mathrm{O}$ expansivo adensamento urbano vem desencadeando a construção de habitações irregulares, promovendo a fragmentação da mata e causando um desequilíbrio ecológico com a inserção de homens, animais domésticos e resíduos, de proporções significativas na região do estudo, tornando-a um importante local para a ocorrência de doenças emergentes e reemergentes (SABESP, 2008).

As amostras foram obtidas de cães de sete pontos dessa região, nomeados de: E1 (234' $50^{\prime \prime}$ 'S $\left.46^{\circ} 41^{\prime} 57^{\prime} \mathrm{W}\right)$, E2 (234'02'S $\left.46^{\circ} 41^{\prime} 14^{\prime \prime} \mathrm{W}\right)$, E3

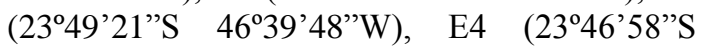
$\left.46^{\circ} 38^{\prime} 18^{\prime \prime} \mathrm{W}\right)$, E5 (2346 $03^{\prime}$ 'S $\left.46^{\circ} 41^{\prime} 36^{\prime \prime} \mathrm{W}\right)$, E6 
(2346'41'S 46 40'42”W), Hovet (2343'50"S $\left.46^{\circ} 42^{\prime} 42^{\prime \prime} \mathrm{W}\right)$; conforme indicado na Fig. 1. As coletas foram realizadas durante as campanhas de esterilização cirúrgica, realizadas pela Prefeitura de São Paulo em convênio com a Universidade de
Santo Amaro. As áreas são de abrangência da Supervisão de Vigilância em Saúde de Parelheiros e da Supervisão de Vigilância em Saúde da Capela do Socorro.
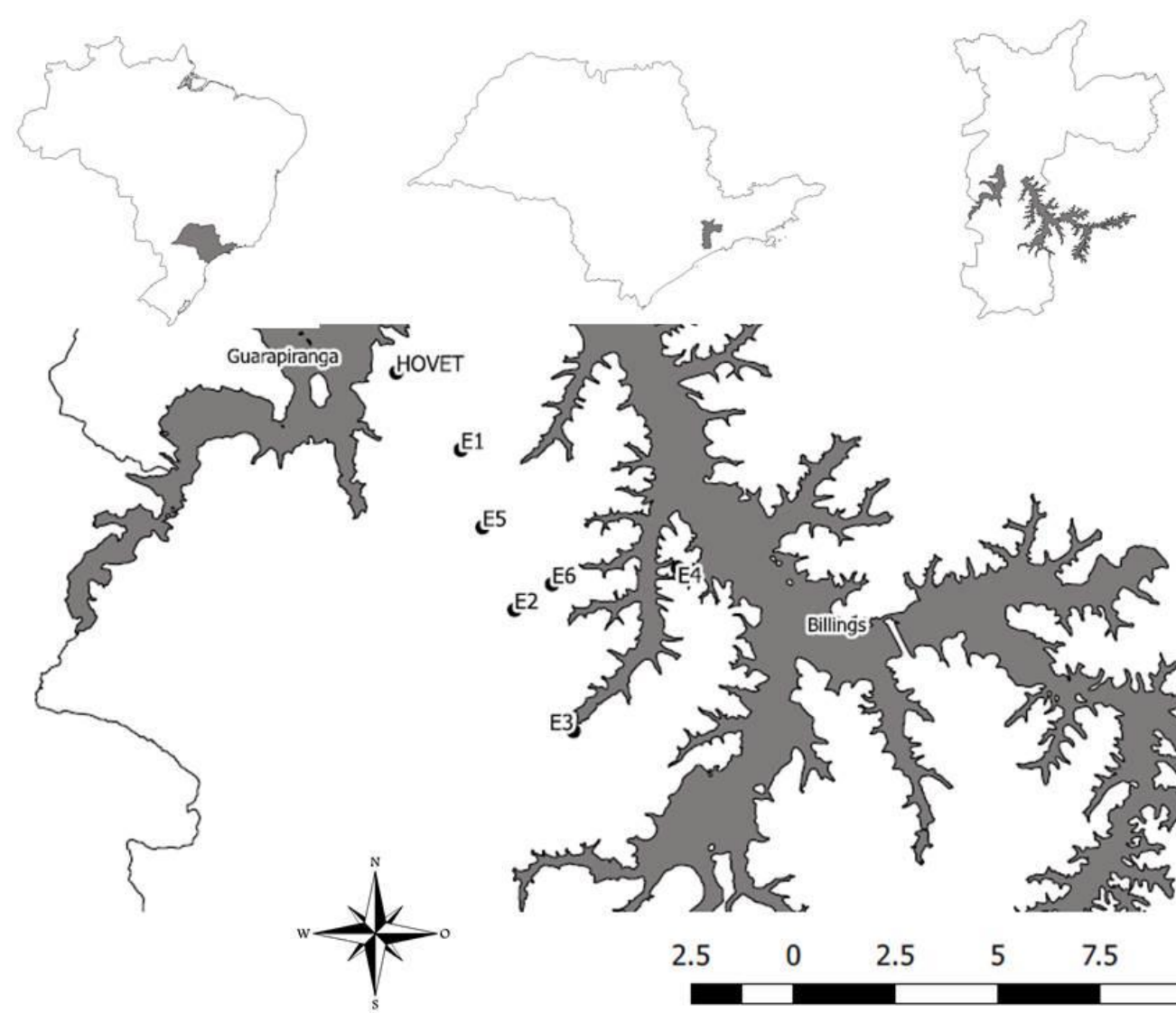

"s

Figura 1. Mapa com os pontos de coleta das amostras dos animais participantes de campanhas de castração submetidas à reação de imunofluorescência indireta para Rickettsia spp., nomeados de E1 a E6 e Hovet, localizados na zona sul do município de São Paulo, SP, Brasil

Todo o procedimento deste estudo foi aprovado pela Comissão de Ética no Uso de Animais da Universidade Santo Amaro (protocolo 04/2016). Foram obtidas amostras de conveniência, de janeiro a dezembro de 2017, de 393 cães, residentes a uma distância máxima de três quilômetros dos locais de coleta, de ambos os sexos, e, antes das coletas, solicitava-se a autorização e o cadastramento do endereço dos tutores. Foram coletadas amostras de sangue, em tubo seco, pela punção da veia cefálica ou femoral, durante a recuperação anestésica da cirurgia de castração. As amostras foram acondicionadas em caixas isotérmicas contendo gelo e levadas ao Laboratório de Doenças
Parasitárias da Faculdade de Medicina Veterinária e Zootecnia da Universidade de São Paulo (FMVZ-USP), onde foram processadas. As amostras foram centrifugadas a $12.000 \mathrm{~g}$, durante 10 minutos, para separação do soro sanguíneo, aliquotadas em microtubos e mantidas a $-20^{\circ} \mathrm{C}$ até o momento das análises.

Os antígenos utilizados foram de $R$. rickettsii (cepa Taiaçu) (Pinter e Labruna, 2006), R. parkeri (cepa At24) (Silveira et al., 2007) e R. bellii (cepa Mogi) (Pinter e Labruna, 2006). Foram utilizadas, como controle positivo e negativo, respectivamente, amostras caninas positiva e negativa para todas as riquétsias testadas, 
publicadas no trabalho de Costa et al., 2017. A RIFI foi realizada e amostras sororreativas foram tituladas conforme protocolo descrito por Horta et al. (2004). Para que uma amostra tenha sido considerada homóloga a determinada riquétsia, esta deve ter apresentado título final, no mínimo, quatro vezes superior às demais riquétsias sororreativas (Horta et al., 2004; Ueno et al., 2016).

\section{RESULTADOS}

Por meio da RIFI, 89 (22,6\%) das 393 amostras foram sororreativas para, pelo menos, um dos antígenos analisados. Parte dessas amostras sororreativas apresentaram títulos para um determinado antígeno homólogo. Porém, nos outros animais, não foi possível determinar qual era a possível espécie de Rickettsia que os animais foram expostos, sendo classificados como soropositivos a Rickettsia spp. (Tab. 1).

Tabela 1. Títulos de anticorpos sororreativos para $R$. rickettsii, $R$. parkeri e $R$. bellii, em amostras de cães residentes nas proximidades dos reservatórios Guarapiranga e Billings, município de São Paulo-SP, Brasil, coletadas entre janeiro e dezembro de 2017

\begin{tabular}{|c|c|c|c|c|c|c|}
\hline \multirow{2}{*}{$\begin{array}{c}\mathrm{N}^{\mathrm{o}} \text { de cães } \\
\text { positivos/ } \mathrm{N}^{\mathrm{o}} \text { de } \\
\text { cães testados } \\
(\% \text { de positivos })\end{array}$} & \multirow{2}{*}{$\begin{array}{l}\text { Local da } \\
\text { coleta }\left(\mathrm{N}^{\mathrm{o}}\right. \\
\text { de cães } \\
\text { testados })\end{array}$} & \multicolumn{3}{|c|}{$\begin{array}{l}\mathrm{N}^{\circ} \text { de cães positivos para cada espécie de } \\
\text { Rickettsia em cada local de coleta } / \mathrm{N}^{\circ} \text { de } \\
\text { cães testados no estudo }\end{array}$} & \multirow{2}{*}{$\begin{array}{l}\mathrm{N}^{\circ} \text { total de cães positivos } \\
\text { para cada espécie de } \\
\text { Rickettsia/ } \mathrm{N}^{\mathrm{o}} \text { de cães } \\
\text { testados (\% de positivos); } \\
\text { intervalo dos valores dos } \\
\text { títulos finais }\end{array}$} & \multirow{2}{*}{$\begin{array}{c}\mathrm{N}^{\circ} \text { total de cães } \\
\text { com } \\
\text { PAIHR*/número } \\
\text { de cães positivos } \\
(\%)\end{array}$} \\
\hline & & $\begin{array}{c}\text { Rickettsia } \\
\text { rickettsii }\end{array}$ & $\begin{array}{c}\text { Rickettsia } \\
\text { parkeri }\end{array}$ & $\begin{array}{l}\text { Rickettsia } \\
\text { bellii }\end{array}$ & & \\
\hline \multirow{7}{*}{$89 / 393(22,6)$} & E1 (23) & $4 / 393$ & $3 / 393$ & $3 / 393$ & \multirow{7}{*}{$\begin{array}{l}\text { R. rickettsii: } 78 / 393 \\
(19,84) ; 64-4096 \\
\text { R. parkeri:56/393 (14,24); } \\
64-512 \\
\text { R. bellii: } 68 / 393(17,3) ; 64- \\
1024\end{array}$} & \multirow{7}{*}{$\begin{array}{l}\text { R. rickettsii: } 13 / 89 \\
(14,6) \\
\text { R. parkeri: } 1 / 89 \\
(1,12) \\
\text { R. bellii: } 16 / 89 \\
(17,97)\end{array}$} \\
\hline & E2 (43) & $9 / 393$ & $6 / 393$ & $7 / 393$ & & \\
\hline & E3 (60) & $14 / 393$ & $10 / 393$ & $11 / 393$ & & \\
\hline & E4 (53) & $9 / 393$ & $9 / 393$ & $6 / 393$ & & \\
\hline & E5 (46) & $11 / 393$ & $8 / 393$ & $9 / 393$ & & \\
\hline & E6 (53) & $23 / 393$ & $13 / 393$ & $27 / 393$ & & \\
\hline & $\begin{array}{l}\text { Hovet } \\
\text { (115) }\end{array}$ & $8 / 393$ & $7 / 393$ & $5 / 393$ & & \\
\hline
\end{tabular}

*PAIHR: provável antígeno envolvido em reação homóloga.

\section{DISCUSSÃO}

A RIFI atualmente é o teste de escolha para o diagnóstico sorológico para Rickettsia em animais e humanos. Entretanto, reação cruzada de anticorpos entre as espécies do gênero Rickettsia é frequentemente observada, o que dificulta a identificação sorológica da espécie envolvida em uma infecção (La Scola e Raoult, 1997; Parola et al., 2005). Assim, padronizou-se que, em soros de animais reativos, será considerado como provável agente aquele que apresentar os títulos, no mínimo, quatro vezes superiores aos outros antígenos analisados (Horta et al., 2004; Ueno et al., 2016).

Sabe-se que $R$. bellii está filogeneticamente relacionada a um grupo basal de riquétsias, em que estão incluídos agentes que infectam, além de carrapatos, anelídeos, insetos e protozoários. Essa bactéria é a espécie de Rickettsia, que infecta a maior diversidade de carrapatos nas Américas (Weinert et al., 2009, Krawczak et al., 2018).
Dessa forma, não é possível determinar qual carrapato pode estar atuando como vetor de $R$. bellii no presente estudo.

Após casos de óbitos por FMB às margens do reservatório Guarapiranga, um inquérito epidemiológico foi realizado na área pela Superintendência de Controle de Endemias (SUCEN) do estado de São Paulo. Foram coletadas amostras de sangue de cães, gatos e equinos. Os equinos apresentaram-se sorologicamente negativos para $R$. rickettsii, enquanto os cães e os gatos apresentaram altos títulos de anticorpos para essa bactéria; o DNA desse agente etiológico, inclusive, foi identificado pela reação em cadeia da polimerase (PCR) em carrapatos A. aureolatum que estavam parasitando os animais no momento da coleta (São Paulo, 2019).

O fato de alguns cães terem apresentado anticorpos homólogos na RIFI para $R$. rickettsii e $R$. parkeri, sugerindo a possível exposição a essas 
riquétsias, pode estar relacionado com as áreas de fragmentação de Mata Atlântica onde esses animais habitam, pois, nesse bioma, o carrapato $A$. aureolatum é encontrado em abundância. Esse ixodídeo pode atuar como vetor da FMB na Região Metropolitana de São Paulo e fora encontrado naturalmente infectado com $R$. parkeri (Pinter et al., 2004; Barbieri et al., 2014; Ogrzewalska, 2012; Scinachi et al., 2017).

Menor positividade foi encontrada nos cães amostrados na área Hovet (Hospital Veterinário da Universidade Santo Amaro), e isso pode ter ocorrido devido à fragmentação da mata e à maior urbanização da área, quando comparada aos demais locais de coleta (E1 a E6). Portanto, espera-se maior densidade populacional dos carrapatos A. aureolatum e de hospedeiros para as fases imaturas e maduras do referido ixodídeo, situação que oferece um cenário favorável para que ocorra a doença (Ogrzewalska, 2012; Scinachi et al., 2017).

Ogrzewalska et al. (2012) realizaram estudos nas áreas de São Bernardo do Campo e Diadema, Grande São Paulo, e observaram que, em regiões endêmicas, as áreas de florestas degradadas, em comparação com as regiões não endêmicas, são mais acentuadas, o que favorece a disseminação da doença para cães domésticos e seres humanos. Tais observações corroboram a soropositividade encontrada nos animais do presente estudo, pois as coletas foram efetuadas em locais de Mata Atlântica fragmentada. Isso reforça a afirmação de que a disseminação da doença está relacionada com a fragmentação e a degradação ambiental, pois A. aureolatum naturalmente realiza seu ciclo silvestre, e, na falta de tal ambiente, o carrapato, para garantir sua sobrevivência, acaba parasitando o cão doméstico e o homem.

O perfil de sororreatividade dos cães do presente estudo é compatível com a circulação de $R$. rickettsii entre cães na região, uma vez que essa espécie de bactéria foi a responsável pelos títulos mais altos nos cães amostrados, assim como a incriminação dela como provável antígeno homólogo em 13 cães $(3,31 \%$ das amostras analisadas).

\section{CONCLUSÃO}

O perfil sorológico, na RIFI para Rickettsia spp., de cães amostrados nas imediações dos reservatórios Guarapiranga e Billings, no presente estudo, indica que a área apresenta riscos de casos humanos de febre maculosa brasileira. Assim, é de grande importância a prática de condutas referentes à conscientização da população, por meio de trabalhos educacionais, ao controle e à prevenção da doença, com constantes atividades de monitoramento da área, realizado pelas equipes de vigilância epidemiológica.

\section{AGRADECIMENTOS}

À Fundação de Amparo à Pesquisa do Estado de São Paulo, pelo suporte financeiro, por meio do processo número 2016/00167-0.

\section{REFERÊNCIAS}

ARZUA, M.; SILVA, M.A.N; FAMADAS, K.M.; BEATI, L.; BARROS-BATTESTI, D.M. Amblyomma aureolatum and ixodes auritulus (Acari: Ixodidae) on birds in Southern Brazil, with notes on their ecology. Exp. Appl. Acarol., v.31, p.283-296, 2003.

BARBIERI, A.R.M.; JONAS FILHO, M.; NIERI-BASTOS, F.A. et al. Epidemiology of rickettsia sp. strain Atlantic rainforest in a spotted fever-endemic area of southern Brazil. Ticks Tick Borne Dis., v.5, p.848-853, 2014.

BRASIL. Ministério da Saúde. Casos confirmados de febre maculosa. Brasil, grandes regiões e unidades federadas. 2000 a 2019. Brasília, 2019. Disponível em: https://portalarquivos2.saude.gov.br/images/pdf/ 2019/junho/14/Casos-de-Febre-Maculosa.pdf. AcessADo em: 15 fev. 2020.

CHEN, L.F.; SEXTON, D.J. What's new in Rocky Mountain spotted fever? Infec. Dis. Clinics N. Am., v.22, p.415-432, 2008.

COSTA, F.B.; COSTA, A.P.; MORAES-FILHO, J. et al. Rickettsia amblyommatis infecting ticks and exposure of domestic dogs to Rickettsia spp. in an Amazon-Cerrado transition region of northeastern Brazil. Plos One, v.12, p.e0179163, 2017. 
SABESP. Dossiê - Sistema Guarapiranga. São Paulo: SABESP 2008. 16p.

FONSECA, F. Validade da especie e cyclo evolutivo de Amblyomma striatum Koch, 1844 (Acarina, Ixodidae). Mem. Inst. Oswaldo Cruz, v.9, p.43-58, 1935.

GUEDES, E.; LEITE, R.C.; PRATA, M.C.A. et al. Detection of Rickettsia rickettsii in the tick Amblyomma cajennense in a new Brazilian spotted fever-endemic area in the state of Minas Gerais. Mem. Inst. Oswaldo Cruz, v.100, p.841845,2005

HORTA, M. C.; LABRUNA, M. B. et al. Prevalence of antibodies to spotted fever group Rickettsiae in humans and domestic animals in a Brazilian spotted fever-endemic area in the state of $S\{\tilde{a}\} o$ Paulo, Brazil: Serologic evidence for infection by Rickettsia rickettsii and another spotted . Am. J. Trop. Med. Hyg., v.71, p.93-97, 2004.

HORTA, M.C.; LABRUNA, M.B.; PINTER, A.; LINARDI, P.M.; SCHUMAKER, T.T.S. Rickettsia infection in five areas of the state of Sao Paulo, Brazil. Mem. Inst. Oswaldo Cruz, v.102, p.793-801, 2007.

KRAWCZAK, F.S.; LABRUNA, M.B.; HECHT, J.A.; PADDOCK, C.D.; KARPATHY, S.E. Genotypic Characterization of Reveals Distinct Lineages in the United States and South America. Biomed Res. Int., v.2018, p.1-8, 2018.

LA SCOLA, B.; RAOULT, D. Laboratory diagnosis of rickettsioses: current approaches to diagnosis of old and new rickettsial diseases. $J$. Clin. Microbiol., v.35, p.2715-2727, 1997.

LABRUNA, M.B. Ecology of rickettsia in South America. Ann. N.Y. Acad. Sci., v.1166, p.156-166, 2009.

LABRUNA, M.B.; OGRZEWALSKA, M.; SOARES, J.F. et al. Experimental Infection of Amblyomma aureolatum Ticks with rickettsia rickettsii. Emerg. Infect. Dis., v.17, p.829-834, 2011.

LEMOS, E.R.; MACHADO, R.D.; COURA, J.R. et al. Epidemiological aspects of the brazilian spotted fever: serological survey of dogs and horses in an endemic area in the state of Sao Paulo, Brazil. Rev. Inst. Med. Trop. São Paulo, v.38, p.427-430, 1996.
MORAES-FILHO, J.; PINTER, A.; PACHECO, R.C. et al. New epidemiological data on Brazilian spotted fever in an endemic area of the state of Sao Paulo, Brazil. Vector Borne Zoonotic Dis., v.9, p.73-78, 2009.

OGRZEWALSKA, M.; SARAIVA, D.G.; MORAES-FILHO, J. et al. Epidemiology of Brazilian spotted fever in the Atlantic Forest, state of São Paulo, Brazil. Parasitology, v.139, p.12831300, 2012.

PAROLA, P.; PADDOCK, C.D.; RAOULT, D. Tick-borne rickettsioses around the world: emerging diseases challenging old concepts. Clin. Microbiol., v.18, p.719-756, 2005.

PAROLA, P.; PADDOCK, C.D.; SOCOLOVSCHI, C. et al. Update on tick-borne rickettsioses around the world: a geographic approach. Clin. Microbiol. Rev., v.26, p.657-702, 2013.

PINTER, A.; DIAS, R.A.; GENNARI, S.M.; LABRUNA, M.B. Study of the seasonal dynamics, life cycle, and host specificity of Amblyomma aureolatum (Acari: Ixodidae). $J$. Med. Entomol., v.41, p.324-332, 2004.

PINTER, A.; LABRUNA, M.B. Isolation of rickettsia rickettsii and rickettsia bellii in cell culture from the tick Amblyomma aureolatum in Brazil. Ann. N Y. Acad. Sci., v.1078, p.523-529, 2006.

PINTER, A.; FRANÇA, A.C.; SOUZA, C.E. et al. Febre maculosa brasileira. Supl. Bepa, v.8, p.32-51, 2011.

PINTER, A.; COSTA, C.S.; HOLCMAN, M.M. et al. (Coord.). A febre maculosa brasileira na região metropolitana de São Paulo. BEPA Bol. Epidemiol. Paulista, v.13, p.3-47, 2016.

RAMÍREZ-HERNÁNDEZ, A.; UCHOA, F.; AZEVEDO SERPA, M.C. et al. Clinical and serological evaluation of capybaras (Hydrochoerus hydrochaeris) successively exposed to an Amblyomma sculptum-derived strain of rickettsia rickettsii. Sci. Rep., v.10, p.1$10,2020$.

SÃO Paulo. Secretaria de Estado da Saúde. Informe técnico Febre Maculosa Brasileira. São Paulo. Centro de Vigilância Epidemiológica Prof. "Alexandre Vranjac". Casos confirmados autóctones de febre maculosa brasileira no estado de São Paulo de 2007 a 2020* por município de LPI e ano do início dos sintomas. São Paulo: CVE, 2019. Disponível em: 
http://www.saude.sp.gov.br/resources/cvecentro-de-vigilancia-epidemiologica/areas-devigilancia/doencas-de-transmissao-por-vetores-ezoonoses/dados/fmaculosa/fmb0720_ano_munlpi .pdf. Acessado em 15/02/2020.

SCINACHI, C.A.; TAKEDA, G.A.C.G.; MUCCI, L.F.; PINTER, A. Association of the occurrence of Brazilian spotted fever and Atlantic rain forest fragmentation in the São Paulo metropolitan region, Brazil. Acta Trop., v.166, p.225-233, 2017.

SILVEIRA, I.; PACHECO, R.C.; SZABÓ, M.P.J.; RAMOS, H.G.C.; LABRUNA, M.B. Rickettsia parkeri in Brazil. Emerg. Infect. Dis., v.13, p.1111-1113, 2007.

SOUZA, C.E.; MORAES-FILHO, J.; OGRZEWALSKA, M. et al. Experimental infection of capybaras hydrochoerus hydrochaeris by rickettsia rickettsii and evaluation of the transmission of the infection to ticks amblyomma cajennense. Vet. Parasitol., v.161, p.116-121, 2009.
SOUZA, C.E.; PINTER, A.; DONALISIO, M.R. Risk factors associated with the transmissionof Brazilian spotted fever in the Piracicaba river basin, State of São Paulo, Brazil. Rev. Soc. Bras. Med. Trop., v.48, p.11-17, 2015.

UENO, T.E.H.; COSTA, F.B.; MORAESFILHO, J. et al. Experimental infection of horses with rickettsia rickettsii. Parasites Vectors, v.9, p.499, 2016.

WEINERT, L.A.; WERREN, J.H.; AEBI, A.; STONE, G.N.; JIGGINS, F.M. Evolution and diversity of rickettsia bacteria. BMC Biol., v.7, p.1-15, 2009. 